\title{
Role of Urban Public Space and the Surrounding Environment in Promoting Sustainable Development from the Lens of Social Media
}

\author{
Thuy Van T. Nguyen ${ }^{1,2}$, Haoying Han ${ }^{1, *}$ and Noman Sahito ${ }^{1,3, * \mathbb{C}}$ \\ 1 Institute of Urban and Rural Planning Theories and Technologies, College of Civil Engineering and \\ Architecture, Zhejiang University, Hangzhou 310058, China; khut_khit@yahoo.com \\ 2 Department of Architecture, Danang Architecture University, Da Nang 550000, Vietnam \\ 3 Department of City \& Regional Planning, Mehran University of Engineering and Technology, \\ Jamshoro 76062, Pakistan \\ * Correspondence: hanhaoying@zju.edu.cn (H.H.); noman_sahito@yahoo.com (N.S.)
}

Received: 5 October 2019; Accepted: 25 October 2019; Published: 27 October 2019

\begin{abstract}
The development of mobile social network has shown the power to change the ways people gather and communicate in urban public spaces (UPSs). In this study, we utilized a check-in database collected from Instagram in 2016 and 2017 in two central districts of Ho Chi Minh City (HCMC) to analyze the city dynamics and activities over the course of the day. By quantifying the popularity of contemporary UPSs, a comprehensive study was conducted on many attraction features spreading over the two central districts. Pearson's correlation was used to explore the proximity and attractiveness associated with the surrounding environment of three types of UPSs. The results show that the lifetime of UPSs is very stable during weekdays and weekends. Within that, commercial UPSs are proved to play a dominant role in urban dynamics. This paper's finding is at odds with the urban planning stereotype that public facilities often help people to get around. In the case of HCMC, it has proved the opposite: people are attracted to urban public spaces even though there are not many cultural and social specialties there. The results will contribute to enhancing the predictability of each UPS on socio-economic performance and to understanding of the role of urban facilities in urban sustainability.
\end{abstract}

Keywords: urban public space; environment; check-in data; social media platform; point of interest

\section{Introduction}

A city is a result of modern human civilization, where people live and work in an extensive and well-developed urban system. However, in the $21^{\text {st }}$ century, cities have undergone a unique period of rapid economic and technological growth. In a case of Southeast Asia, Dick and Rimmer [1] mentioned Asian exceptionalism. Their arguments suggest that the motion of Southeast Asia's new urbanization would be the avoidance of social discomfort. Urban geography of the region features in the movements between public and private space, which can take place from diverse dimensions: center to periphery, periphery to periphery, center to center, or periphery to center [2]. Along with modernization and globalization, urban public space, which is a traditional connotation in urban planning, now faces an inevitable transition in the new era. Urban public spaces (UPSs) indeed have acquired a renewed visibility in urban planning discourse as an essential ingredient of urban sustainability. Therefore, the major difficulty for authorities is to create and sustain public goods in a manner that distributes proportionally health, well-being, viability, and economic benefits. Hence, investigating the UPSs use and its correlation helps us understand how it can bring out different socio-economic benefits. 
In defining public space, it is essential to consider the meaning of the term "public". Madanipour [3] suggests that "the word public originates from the Latin and refers to people, indicating a relationship to both society and the state". This suggests that "public" may be any entity, regardless of whether tangible or not, that relates to people and is shared by and open to them in a community as a whole. The concern here is space as the physical entity that is linked to the term "public". This provides a basic understanding of public space as the space that concerns people and may be interpreted "as the space open to people as a whole" [3]. These ideas are echoed in the various definitions of public space.

Public space plays an important role in sustaining the public realm. There is a renewed interest in public space with a growing belief that while modern societies no longer depend on the town square or the piazza for basic needs, good public space is required for the social and psychological health of modern communities. New public spaces are emerging around the world and old public space typologies are being retrofitted to contemporary needs. Good public space is responsive, democratic and meaningful. However, few comprehensive instruments exist to measure the quality of public space [4-7].

According to Carr, et al. [4], a true urban public space should be responsive, democratic and meaningful. Responsiveness of a public space requires that it should serve the needs of its users such as comfort, relaxation, active and passive engagement and discovery. Democratic public space, which should be accessible to all groups, is that which protects the rights of its users.

Over the last two decades, UPSs have been the subject of considerable debate. There are theories and beliefs about the knowledge of urban design and, in particular, public places, which have always focused on the role of space characteristics in the production of urban spaces [8]. Some physical and social factors of environment can have impact on the selection and utilization of UPS in developed countries [9]. Many recent reviews have studied relevance between proximity and use of UPS at an intense volume of physical activity [10], and the vital elements and their intricate interaction influence the use of UPS such as sociability [8], behavior of individuals and groups in small UPSs [11], design elements in public spaces [12,13] accessibility [14-16] and the surrounding environmental factors [17-19]. Specifically, the presence of facilities is thought to become the most essential element reflecting UPS, in particularly urban green zones [20,21]. Nevertheless, these reports were mostly in developed countries, which had social and economic constraints according to diverse contexts.

Brown indicated that sustainability should construct the balance between the natural environment and artificial configurations [22]. The built environment is an essential element of sustainable society [19]. Focusing on the typical urban spaces in the city, such as: open spaces, commercial space, etc... This paper aims to study the relationship between the surrounding environment and UPSs utilization in low- and middle-income countries. Nowadays, due to the restricted space, unsafety, noise and air contamination of previous public spaces [23], along with an emergence of financially-driven urban redevelopment processes, commercial-related public spaces (such as restaurants, cinemas, and shopping malls) have become the new civic centers and social hubs in contemporary cities $[24,25]$ This new phenomenon is posing crucial questions: how do the people experience these urban public spaces in the city? Vice versa, how surrounding contexts, have influence on people's choice of gathering could also become a good research question. Answering these two issues may lead to a more insightful understanding of spatial-temporal needs for the daily life of local communities.

Often conventional methods for large scale data-collecting are labor-intensive, hence too costly; which turns out to be a drawback in the research practice on people's spatial and temporal activities. Recently, however, fast-advanced technology has given way to many practical innovations, especially in the field of the Internet. It is also worth noting a new development of geographic science [26], which is demonstrated by a huge number of geographic attachments of "geo-tagged" data providing both the latitude and longitude coordinates [27-29]. In spite of this promising potential for new studies, there are some specific constraints of the exploration of social media data, namely issues of sampling, situation-related unreliability, and also deprivation of theoretical firmness [30]. Nevertheless, after being carefully refined, the check-in database has an advantage to answer different questions over 
traditional data, which is often combined and outdated [29]. Point-of-interest (POIs) and check-in data in social media, a refined dataset obtaining more information, are becoming new focal subjects in urban study, which allow us to examine how new communities rise and form sociocultural norms in the online world [31,32]. Instagram is regarded as a socially visual-locative means, which can contribute as a participatory sensing system $[33,34]$. By using Instagram data to record urban dynamics, it is found that spatiotemporal models are correlated with routine activities of citizens. Consequently, Instagram has the capability of identifying the places of cultural activities [27,35].

In this paper, with consideration to the spatial-temporal dimensions and activity categories for analysis, we aim to give the detailed descriptions of citizens' activities. Relying on the Instagram platform, the research intends to collect people's check-in data in Instagram, then keep track of and analyze relevant information of UPS. UPS is framed to be the organic combination of the place itself, and a destination for people to stay and carry out activities, which results in a particular geographic space and other surrounding environmental, infrastructure, and relevant conditions.

We conducted research in Ho Chi Minh City (HCMC) in Vietnam. HCMC is the biggest city in Vietnam. From a literature review, we found that there are few studies on urban public spaces in HCMC and no study is present using people's check-in data in Instagram methods. Therefore, in this study, with help social media check in data POIs we have three research questions: what are the social characteristics of urban public spaces? Which are most preferred/visited urban public spaces throughout the day? Why are hotspots located at different times during weekdays as well as weekends and are causes of attractiveness in urban public spaces?

This paper follows this order: Section 2 will go through related literature review on this field; Section 3 will demonstrate the methodology and dataset in detail; Section 4 will present our results; finally, Section 5 comes to conclusions with suggestions for further studies.

\section{Literature Review}

\subsection{Urban Public Space (UPS)}

In the last 20 years, public spaces have adapted to people's changing behavior, which consequently needs a renewed observation on urban planning discourse. Conventional wisdom holds that public spaces, playing a role as a vital element for urban sustainability, are now becoming indispensable keys to the formation of inclusive communities and more specifically, enhancing public culture and cultural diversity [36]. The term "public space" here also refers to more commercial-related public sites of consumption (such as café shops), because these spaces usually perform the same social role as a space for sociality and recreation. In short, public spaces allow people to "assemble and socialize away from home and work", where Oldenburg observed and coined the connotation "Third place" [37]. Nguyen et al. added the book-store café as a "third place", which emphasized that these are places where people can gather for casual occasions, yet this important sociality can be without excessive social or personal obligations [38]. However, public spaces recently have not always purely served the public. Low [39] pointed out the relation of the privatization and commercialization of public spaces by corporate or commercial interests, claiming that "during the past 20 years, privatization of UPSs has been significantly increasing, concerning with the closing, redesign, and regulating of public parks, the building of malls, departments or plazas, the opening of central business districts that have certain control over local streets and parks, and the transfer of public air rights for the commercial buildings ostensibly open to the public". This trend may simply raise awareness to broaden the definition of public spaces; specifically, to incorporate some of the new forms of commercial-related public spaces that have been thriving in urban society. Later, Banerjee [40] suggested that urban planners should keep close attention to broader notions of public life, instead of merely physical public spaces, given the new reality that many public activities exist in private spaces, as they are "not just in incorporate theme parks, but also in small businesses such as coffee shops, bookstores ... ". Moreover, there is also a growing interest in re-establishing the correspondence between public space and urban mobility. 
Empirical studies have shown that a warm welcome for attractive public spaces, which also comprise mobility hubs (like stations, airports, bus stops), as well as the use of commercial-related public spaces [19] (for instance, department stores and commercial complexes) add more key challenges for an innovative design of viable mobility systems and a goal for sustainable and livable cities.

\subsection{Geo-Tagged Social Media-Related Study}

A strong rise of social media platforms along with an outburst of smartphones have helped many generations, especially youth, to share their daily routines and activities on the Internet, also known as the online community, which means to create their digital footprint in urban areas. Undoubtedly, this newly emerged community along with its digital data turn out to be precious sources for academic urban behavior research. Moreover, it has recently been recognized that data collection of social media can help provide reliable geographic information in replacement of conventional data-collection methods [41].

Currently, geo-tagged social media and Global Positioning System (GPS) tracking data have been claimed to further understand human mobility patterns as well as spatiotemporal models [42,43]. Although there are several platforms that have more users globally, Twitter is so far the most popular platform to extract geographic data [41]. For instance, Tsou [44] demonstrated an academic method for recording and investigating the spatial content of Twitter which helps enable analysis of social events from a spatial temporal perspective. Studying social media "check-in" pattern hence contribute a more profound rationale of urban dynamics [45]. In 2012, Frias-Martinez [46] demonstrated another framework to identify land use structure by geo-tagged tweets in Manhattan, London, and Madrid, claiming that these data can provide a compatible statistical input for local governments. Having said that, researchers trying to rely on the geo-tagged data might be concerned with social media platforms that do not simply show the citizens' movement patterns. Different platforms might have different preferences, such as Twitter for updating news and Instagram for everyday photos and videos [47], or levels of posting immediacy [48]. Foursquare and Instagram both demonstrate almost identical urban features (population), and also show distinctions: Foursquare distributes better user routing data, while Instagram illustrate better cultural behaviors of users [35].

Instagram users are believed to be picky about showcasing their lifestyles and personal images that they feel suited for acquaintances or followers [49]. This implies that they choose to represent the city and their places with a highly curated content. By connecting with other users in cyberspace and tagging the same locations, Instagram users create communities on both online and offline worlds. Consequently, by demonstrating places where the association takes place, we can explore and examine how communities really rise and develop at the two interfaces and then create social and cultural contexts. This provides an impressively innovative approach as before such data could only be collected and processed by surveys or observation settings, but now we can access social media to collect much more data at a much shorter time, and to conduct a comprehensive investigation of how citizens interact and assemble with each other.

\section{Methods}

\subsection{Analysis of Spatial Distribution Patterns}

In order to detect where check-in posts are, a grid mapping is virtualized by 100 -meter $\times 100$-meter grid-size squares. The purpose and number of visiting inside each square is also examined. This helps generate activity spatial distribution maps by pointing out the frequently-hit places as well as their main functioning. Citizens' activities are very diversified at different periods of time in one day, weekdays, and between weekdays and weekends [50]. When check-in mapping shows contrasts for multiple activity groups, this suggests a high effect of urban areas on people's visiting choices. 


\subsection{Indicators of UPSs' Visitation Rates}

To evaluate how the surrounding built environment influences the UPS, we examined two design indicators: 1) UPSs' check-in times 2) the surrounding built environment. For UPSs' check-in times, we counted the check-in times which stipulate the attractiveness of the particular space towards the people. We hypothesized that UPSs themselves have their own surrounding advantages, which include the inside facilities and its characteristic, such as, area of a place, the environment, the interior decoration, etc. At the level of neighborhood, we evaluate transportation access and other surrounding attractive places, and we assumed that one place would attract or accommodate more visitors. The neighborhood characteristics are computed using a kernel density estimation (KDE) procedure [51].

$\mathrm{KDE}$ is a method that produce representations of local density estimates from two-dimensional point perspective, hence becoming an effective tool for analyzing projected hotspots, estimating intensity and visualizing the distribution of points by spreading a radius by a kernel function with defined bandwidth [52,53]. To Schabenberger and Gotway [54], the KDE can be calculated as Equation (1)

$$
f_{(s)}=\sum_{i=1}^{n} \frac{1}{h^{2}} k\left(\frac{d_{i s}}{h}\right)
$$

where $f_{(s)}$ is the KDE function at the location, $h$ is the bandwidth, $d_{i s}$ refers to the distance from point $i$ to $s$, and $k$ the classic Gaussian kernel function.

\subsection{Correlation Coefficient Modelling}

To evaluate how the surrounding built environment has influence on UPS visitation, we examined two design indicators: 1) UPSs' check-in times $D p$ and 2) the surrounding built environment $D k$ as below:

The UPSs' check-in times: The UPSs's check-in times is counted as the check-in times which stipulates the attractiveness of the UPS towards the people.

The surrounding built environment $\mathrm{D}_{\mathrm{k}}$ : Assuming that the attractiveness of each POI is not only relied on its own endowed advantage, but it is also remarkably influenced by the surrounding environment, such as locations, traffic conditions, and many other external factors. In this study, we assumed that the surrounding environment include all neighborhood accessibility variables at the neighborhood level, such as public transportation (bus stops), public facilities (parks and shopping malls), and other commercial spaces. The KDE then examines the point distribution of adjacent domains (with $h$ bandwidth). The choice of $h$ bandwidth strongly affects the resulting surfaces. As the study was mostly concerned with the fine-scale of the city, we defined the neighborhood of each UPS as a 400-meter buffer zone. The reason is that previous studies suggested 400 meters would be a primary maximum walking distance based on 5 to 15-minute maximum walking times in transit design guides [55]. Thus, we chose 400 meters as the value of $\mathrm{h}$ bandwidth in the KDE calculation.

Next, we use a geographic information system (GIS) to collect and sort out data. Assuming that the $D_{p}$ and $D_{k}$ are in different units, the standardization stage was processed to put different variables on the same scale. This stage allows to compare scores between different types of variables.

In order to indicate whether the choice of people of any space related to the surrounding facilities or not, Pearson's correlation (Pearson's R) was used as a statistical measurement that helped to calculate the strength of the relationship between the advantages of external factors and the UPSs visitation. The value range varied from -1.0 to 1.0. A correlation of -1.0 showed a perfect negative correlation, meanwhile, a correlation of 1.0 showed a perfect positive correlation [56]. The correlation coefficient is formulated as below:

$$
R=\frac{\left(\sum_{i=1}^{n} D_{p} D_{k}\right)-\left(\sum_{i=1}^{n} D_{p}\right)\left(\sum_{i=1}^{n} D_{k}\right)}{\sqrt{\left[\sum_{i=1}^{n} D_{p}^{2}-\left(\sum_{i=1}^{n} D_{p}\right)^{2}\right]\left[\sum_{i=1}^{n} D_{k}^{2}-\left(\sum_{i=1}^{n} D_{k}\right)^{2}\right]}}
$$




\section{Materials}

\subsection{Case Study}

HCMC is famous as the business and financial center of Vietnam, as well as a popular tourist destination. With a population over nine million, HCMC nowadays has become a host for a large number of energetic people in the nation, particularly the young. Especially, with the dynamics of ongoing urban sprawl, agglomeration has resulted in HCMC being the first megacity in Vietnam [57]. This study was based on Instagram check-in data within two districts (district 1 and district 3 ) in the center of HCMC. The analysis unit for studying urban activities is considered different based on the borders of municipal administration units, for example, neighborhood and traffic zones, because the latter are too broad to tell apart the features of urban activities and assure sufficient accuracy. Therefore, the analysis unit was a 100-meter $\times 100$-meter grid. This grid unit serves the calculation of hour-based check-in numbers and coordinate the output with POI data.

\subsection{Data Collection}

Points of Interest (POI) are particular location of points, for example, shopping malls, office, restaurant, open spaces, which provide a tool for location-based services. The POI data was chosen because: (1) POI data has good adaptability for scaling problems, (2) by people's interaction, POIs help show their personal biases and also a place's social roles (3) statistical gridding of POI data is much finer, hence providing more comprehensive information [58,59].

Street networks are collected from OpenStreetMap (OSM). OSM is a team-worked web-mapping project that collects geospatial data in online maps which often offers country downloads [60]. In our study, we obtained all the locations of public transportations from the Google website.

A check-in database is a set of geo-tagged data which can be used to record people's movements at one time and place. Hence, a large-scale set of check-in data can help us extend our perspective on people's actual activities in terms of space and time [61]. Launched in 2010, Instagram has been the worldwide social network platform for photo and video sharing [62]. As a result, Instagram, which can be regarded as socially visual-locative means, can contribute as a participatory sensing system [33]. This study uses data crawled from the Instagram Application Program Interface (API) platform over two successive years (from January 2016 to December 2017). Only geo-tagged posts from two central districts were selected. Besides the crawling coordinates, each Instagram user also carries information about the user ID, the link of each post, check-in time, and check-in locations. In total, we downloaded 142,620 posts within district 1 and district 3 of HCMC.

Identification of activity categories: Geo-tagged social media platform is valued for the capability to identify activity sets. When queried in the location-based service provider, this link provides information about the categories based on the visited venue. After that, we manually verified and, when needed, merged the place names. This research paper classifies all of the obtained POIs into 7 types based on type of the visited locations as well as according to Mathew Carmona's classification of UPSs [63], namely Open Space, Food and Drink, Life Service, Art and Entertainment, Shopping, Residence and Office; Education (Table 1). Also, Figure 1 demonstrates the POIs in each category. Then, the mixing POIs, including open space-oriented POIs (OS-POI), commercial-oriented POIs (C-POI) and other-oriented POIs (O-POIs) were categorized and assessed. A number of each OS-POIs, $\mathrm{C}$-POIs, O-POIs were calculated in the designed grid. Here, OS-POIs comprise open public spaces such as park, square, etc. In contrast, C-POI includes food and average, shopping services, life services, art and entertainment. O-POI consists of residence, office and education.

However, check-in data has several constraints, namely sampling bias or location inconsistencies. Therefore, some standards were applied to refine the check-in data [64]: (1) POIs not covered in study area were removed; one or two-time check-in POIs were taken out; (3) user accounts having only one check-in were considered invalid; and (4) in 30-minute blocks, users who checked in more than once at the same place were counted as one record. After filtering, 66.055 check-in records are kept, with 344 
POIs (Figure 1, Figure 2). Next, GIS software (ArcGIS 10.4) received all the data, and made a layer of $\mathrm{x}-\mathrm{y}$ coordinated points, then each point was illustrated (Figure 3).

Table 1. Activity category classification.

\begin{tabular}{cr}
\hline Activity Category & Type of Visited Location \\
\hline Open Space & Park, Square, Playground, Streets, etc. \\
Food \& Drink & Coffee shop, Tea house, Restaurant, Pizza, Pub, Nightclub, Bar. \\
Life Service & Gym, Spa, Nail, Salon, etc. \\
Art \& Entertainment & Entertainment, Theater, Concert Hall, Event Space, etc. \\
Shopping & Supermarket, Plaza, Pharmacy, Mall, Boutique, Bookstore, etc. \\
Residence and Office & Residential building, Office, etc. \\
Education & School, College, University, etc. \\
\hline
\end{tabular}

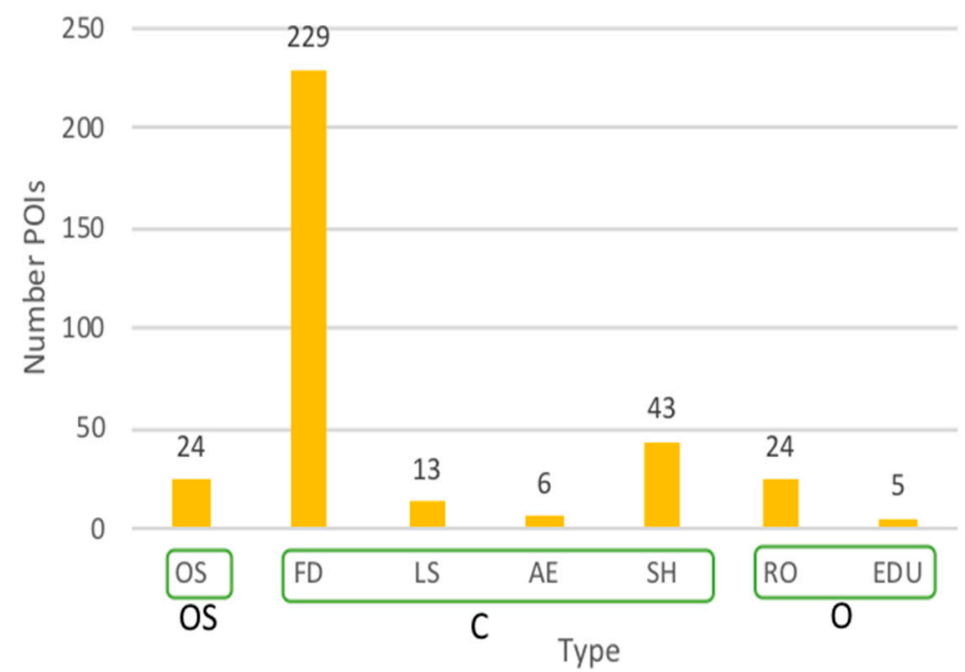

Figure 1. Total number of points of interest (POIs) in each category. Note: OS: Open space; FD: Food and Drink; LS: Life Service; AE: Art and Entertainment; SH: Shopping; RO: Residence and Office; EDU: Education; C: Commercial-oriented POI; OS: Open space-oriented POI; O: Other. Source: Authors.

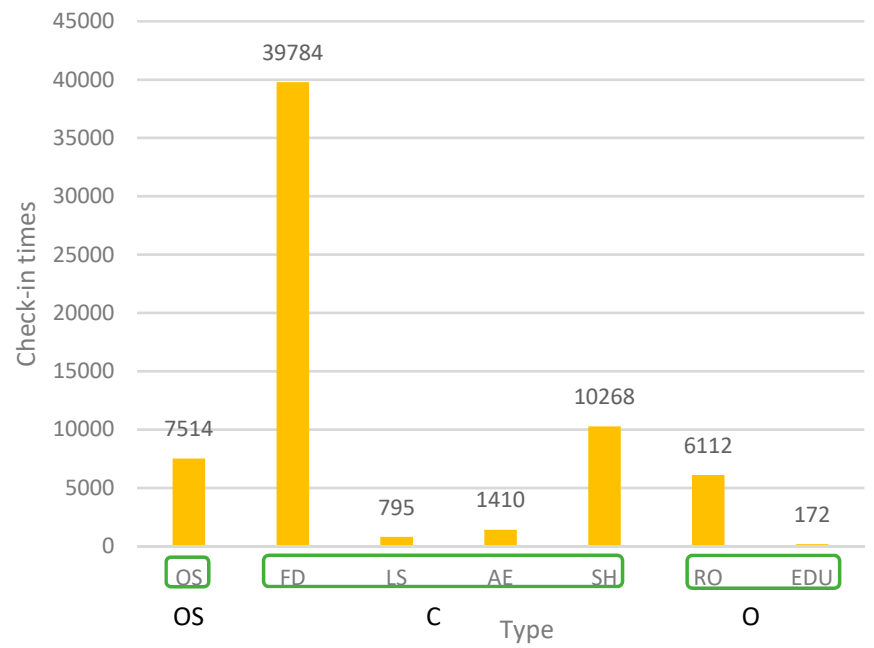

Figure 2. Total number of check-ins in each category. Source: Authors. Note: OS: Open space; FD: Food and Drink; LS: Life Service; AE: Art and Entertainment; SH: Shopping; RO: Residence and Office; EDU: Education; C: Commercial-oriented POI; OS: Open space-oriented POI; O: Other 


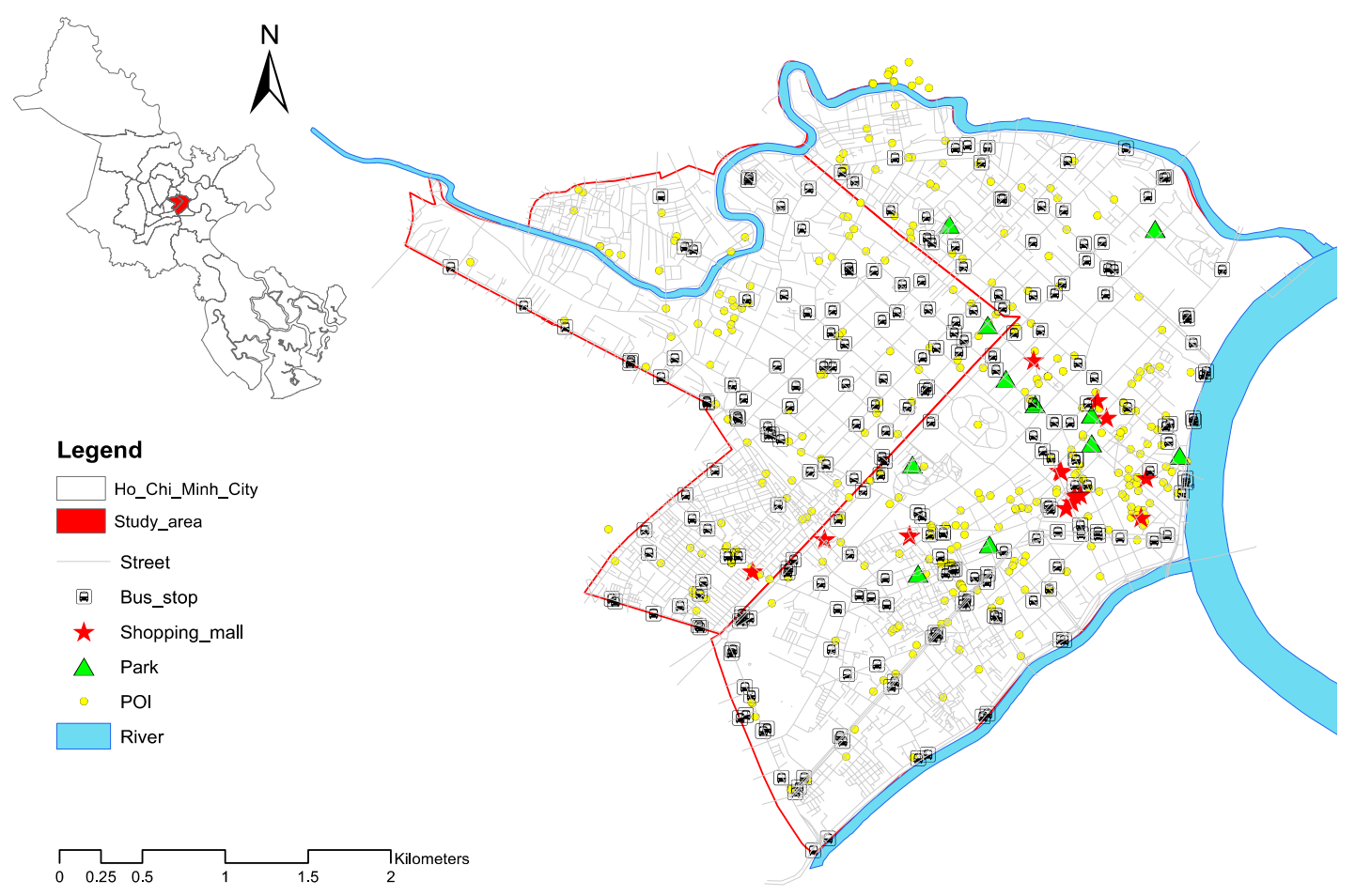

Figure 3. Spatial grid and check-in data in the study area. Source: Authors.

Normalization of data and calculation of the number of check-ins during period time of day. Figure 4 shows the one-hour time intervals of Instagram posts frequency within the two districts throughout 24 hours. The frequency of Instagram posts fluctuates considerably as social media is used the most during the evening time. The peak time occurred at $9 \mathrm{pm}$ (6386 posts), whereas this figure fell to 1530 posts at $8 \mathrm{am}$. Subsequently, the data was aggregated into 5 time slots to facilitate analysis.

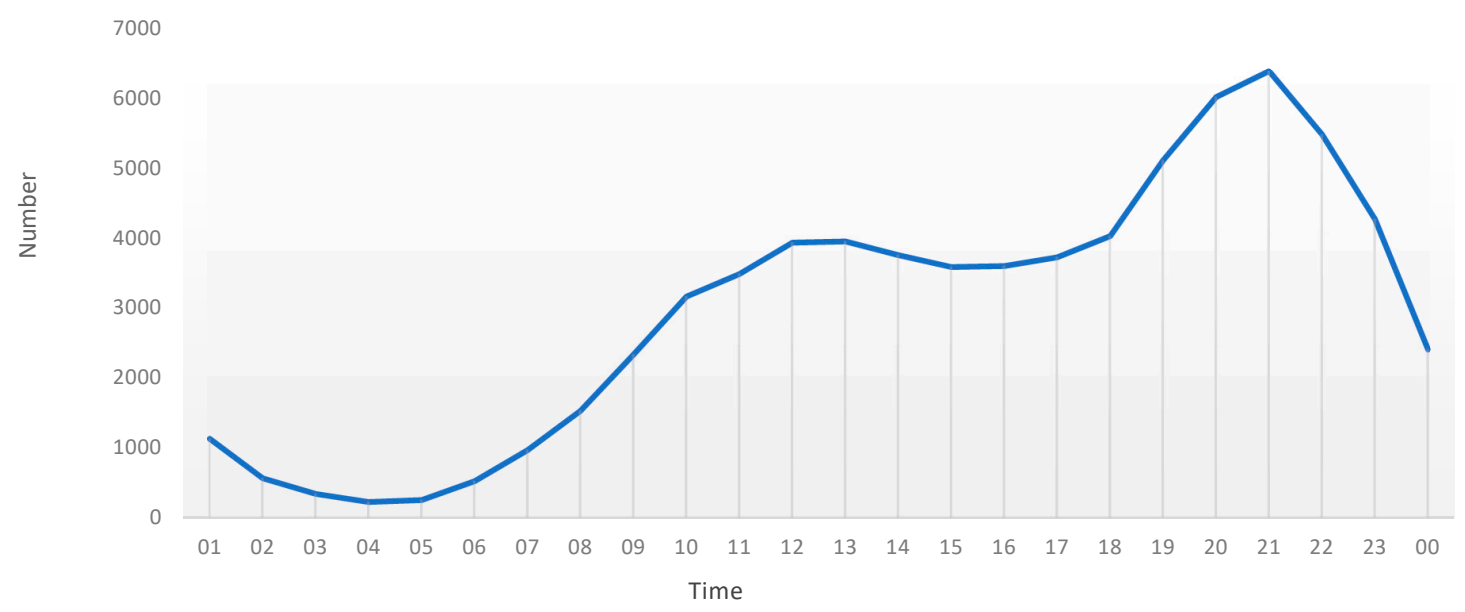

Figure 4. Temporal check-in densities for different activity categories.

\section{Data Analysis}

\subsection{Spatial Distribution of the Most Popular Spaces}

Figure 5 shows the spatial distribution of different activities in district 1 and district 3 of HCMC. For this study, urban activities are divided into specific timeslot with a division of per day, per weekdays, and between weekdays and weekends [50]. 
We counted the total number of check-ins for different activities within 24 hours in the 100-meter $\times 100$-meter grid during weekdays and weekends. Subsequently, the Instagram activity and land use were linked and compared. By performing descriptive analysis based on the crawling data of geo-tagged Instagram posts in accordance with the predominant area in two central districts, Figures 5 and 6 show that for most activities related to C_POI spaces, the clear radiance becoming bolder from the morning to the evening, from weekdays to weekends, except for OS_POI areas (which had a pretty fair radiance) and O_POI areas (which showed more activity during weekdays rather than weekends). In HCMC, by an outnumber of Instagram check-in posts, commercial spaces take over a dominant role in citizens' lifestyle compared to open spaces, regardless of weekdays or weekends (as shown by Figure 5(a1,a2,b1,b2)). However, there are contrasting trends of two types of spaces: open spaces have fewer activities during weekends along with the shrinking size (Figure 5(a1,a2)); meanwhile, commercial spaces gain attractiveness in more diverse areas, particularly the periphery of research scope (Figure 5(b1,b2)). Therefore, in terms of spatial distributions, a visible contradiction can be detected among public spaces, commercial spaces and other spaces, with a growing tendency of leisure activities in commercial spaces; and the areas of public activity in open spaces, which were much more active during the daytime, meanwhile other spaces are not remarkable.

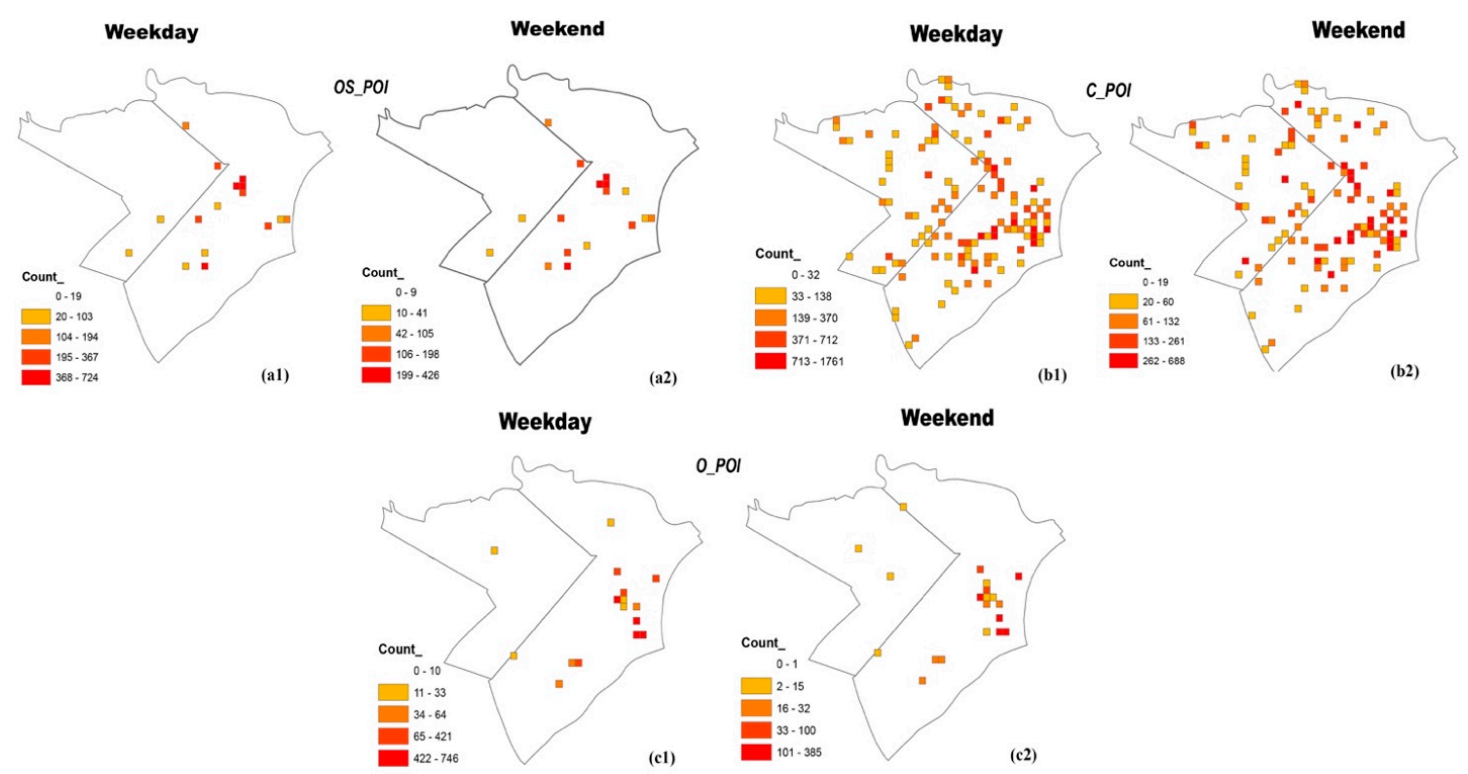

Figure 5. Spatial distributions of different activity categories.

\subsection{Temporal Mobility Patterns}

To display the temporal frequency of the two central districts' mobility, we examined the distribution of visits for activity purposes throughout different time courses of the day (see Figure 6). We also investigated the weekly regularity of these visits. Impressively, the number of commercial spaces have the most regular and highest visiting frequency compared with open spaces and other spaces (approximately 10 times higher). During the day, each space has two distinctive peaks: 12:00 and 20:00, noted that nightlife's activities are two times higher. There is also a fairly stable distribution among three investigated spaces, however, we can observe that weekends fairly host more activities than weekdays, regardless of space categories.

\subsection{Kernel Density Estimation of Temporal-Spatial Distribution of the Popular Spaces}

We conducted a kernel density analysis to find the density of each cell for all activities in different categories in 2-hour intervals. This Kernel Density Estimation (KDE) analysis helps comprehensive research on the vibrant transformation of activities in terms of both space and time. Figure 6 below 
shows the kernel density estimation results for district 1 and district 3 in HCMC, which point out the pattern of citizens' activities.

As for the spatial allocation, the central area at Ben Nghe ward presents obvious high frequencies and densities, especially the main agglomeration area which is bordered by the most crowded streets: Le Thanh Ton street, Nam Ky Khoi Nghia street, Ham Nghi street and Le Loi street; besides, there is also a high agglomeration near Notre-Dame Cathedral Basilica of Saigon. From the temporal perspective over space, people's activity frequencies are relatively high at 8:00-10:00; 12:00-14:00 and 18:00-20:00, which are associated with the eating time (breakfast, lunch and dinner) as well as the leisure nighttime for hanging out.

As shown in Figure 7, it is noteworthy that the permanently dense hotspots are also the most bustling and lively locations of HCMC in terms of individual density. Besides, stability both in space and time is also observed in the city center.

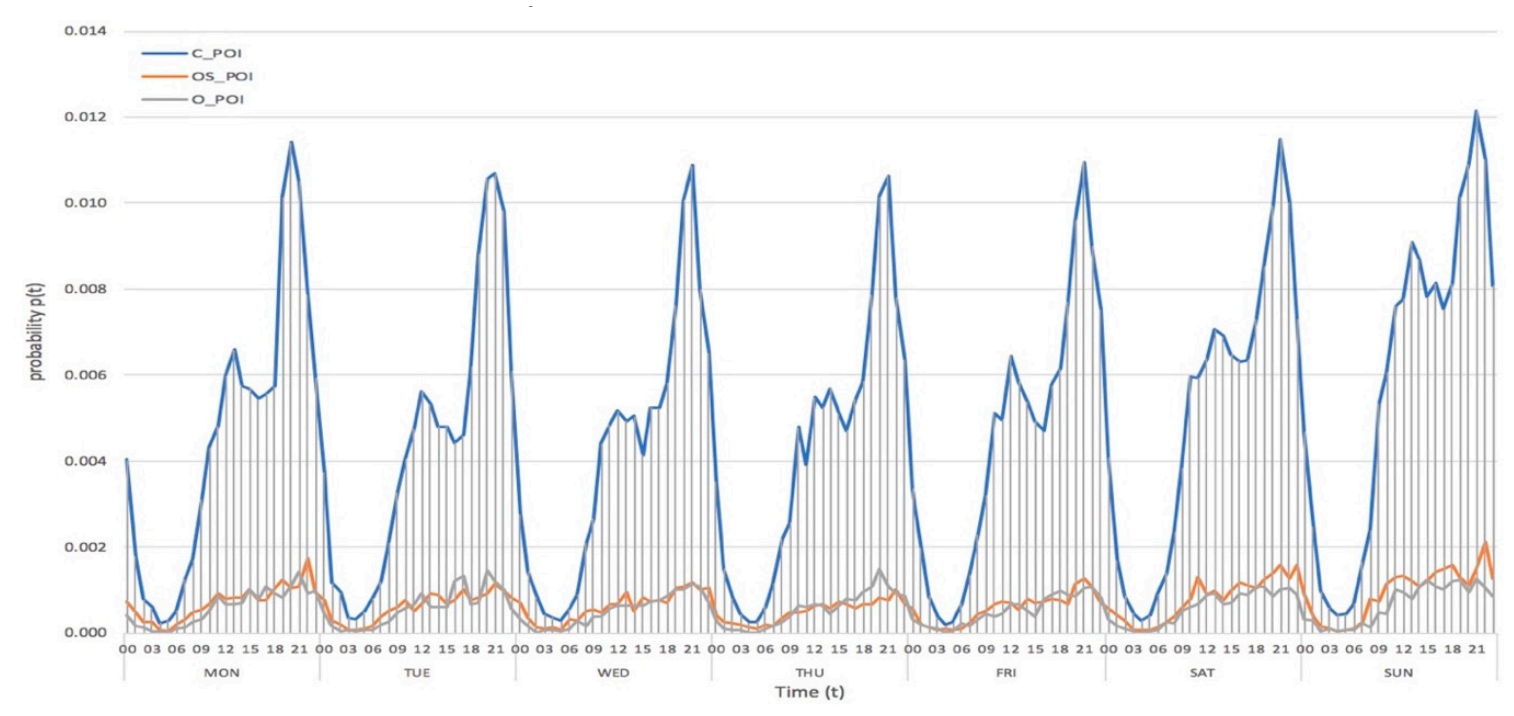

Figure 6. The average daily temporal trend $(24 \mathrm{~h})$ of Instagram posts in the study area.

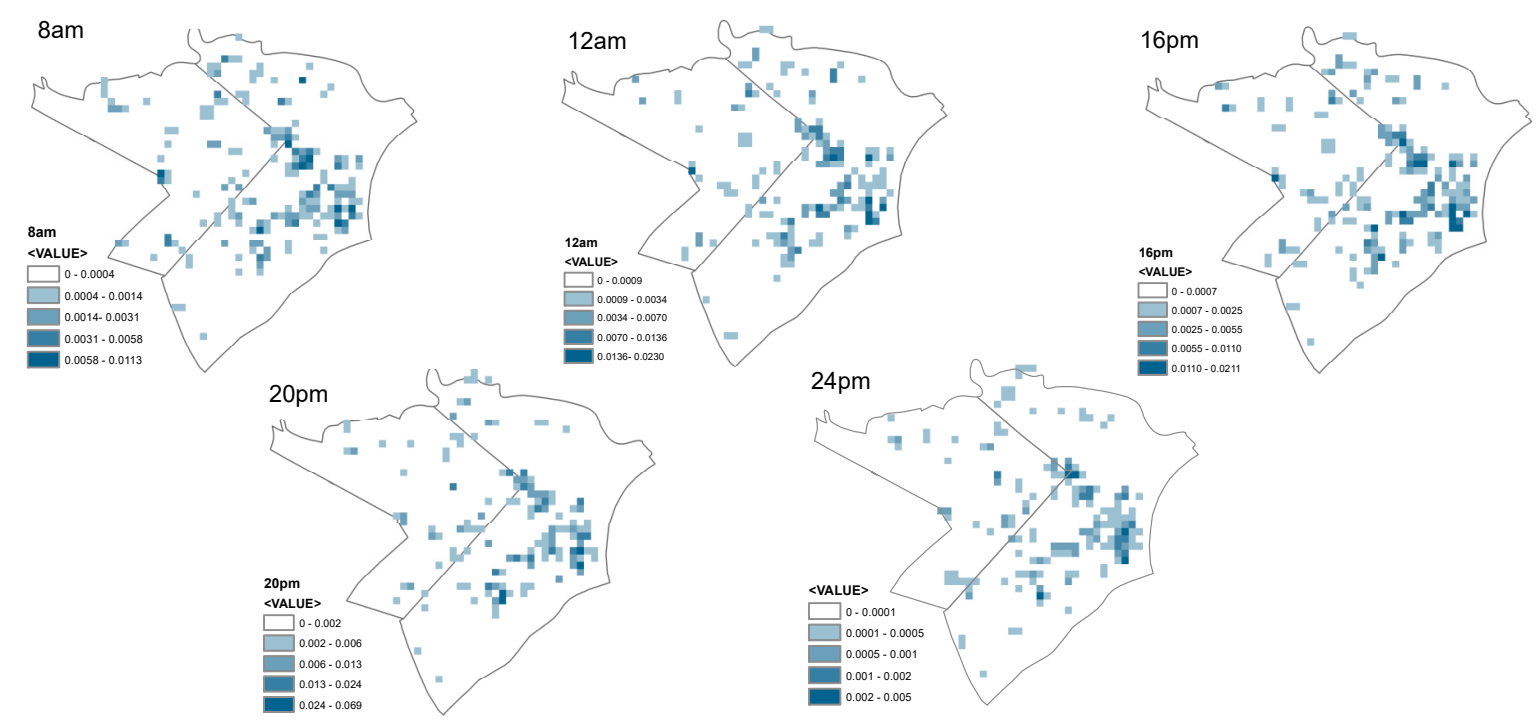

Figure 7. Kernel density estimation results of the check-in densities at different times. 


\subsection{Correlation Coefficient}

Based on Equation (2) above, we examined a correlation coefficient of check-in numbers and kernel density estimation as shown in Figure 8. In the same group, the correlation coefficient can help facilitate the relation of scores among different measures. Accordingly, an intense direct relationship is considered as a high value (advancing toward +1.00 ), values around 0.50 are moderate, whereas a loose relationship are values below 0.30 . In contrast, an intense inverted relationship is considered as a negative value (advancing toward -1.00 ), and values about 0.00 mean little or no relationship [56].

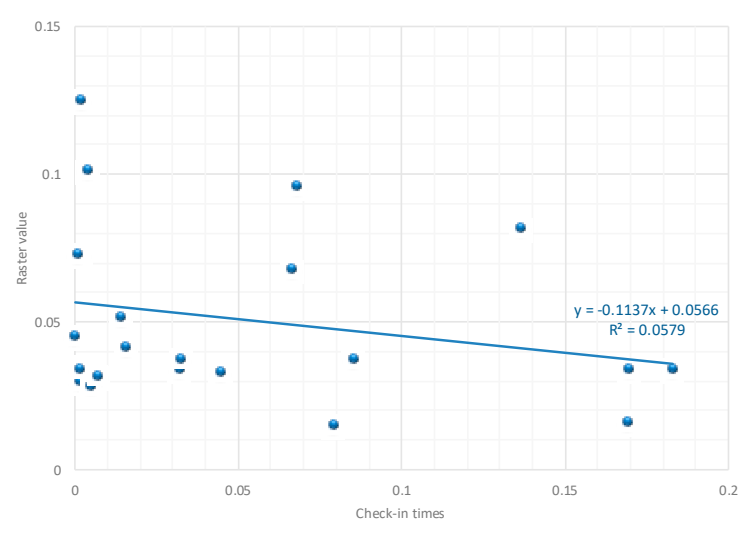

OS_POI $(R=-0.24054)$

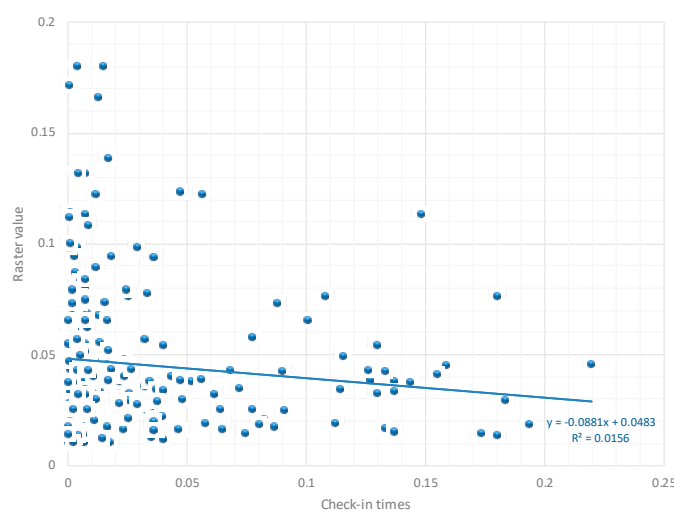

$C_{-} P O I(R=-0.12474)$

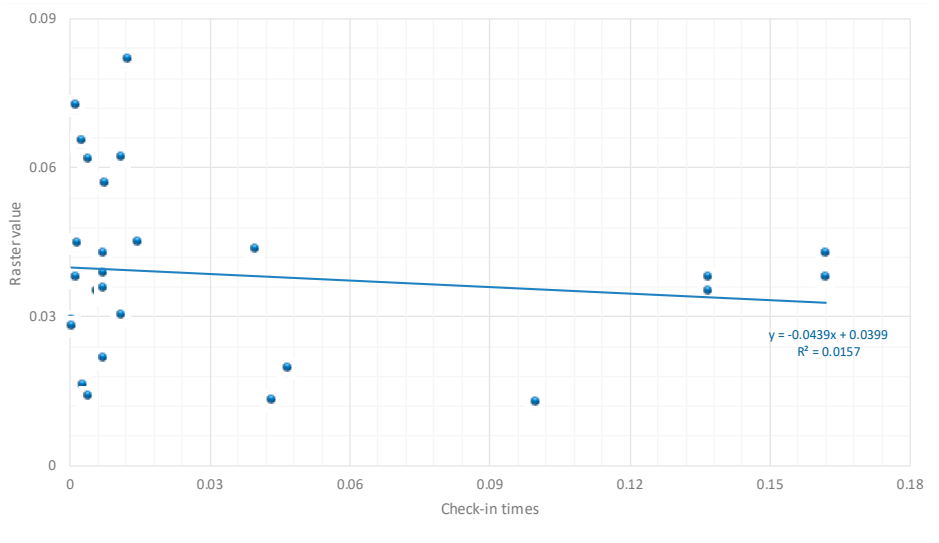

O_POI $(R=-0.12524)$

Figure 8. Pearson's corelation coefficient.

As shown in Figure 8, the $\mathrm{R}=-0.24$, POI of Open Spaces revealed a relatively weak negative relationship between check-in data and the surrounding facilities. Meanwhile, with $R=-0.12$, both Other Spaces and Commercial Spaces showed little or negligible relationship. This result, surprisingly, implies that surrounding built environment has almost no influence on the attractiveness of one urban space.

\section{Discussion and Conclusions}

An assistant of big data for urbanization issues is more widely accepted due to the fast development of technology and the expansion of many social media platforms. Social media data is quite time-sensitive, a special characteristic, which can reflect status in real time. More importantly, it is a kind of public participation, which make it cheap and easy to collect. In this research paper, we used data from Instagram, which is one of the most popular social networks for Vietnamese citizens, to analyze their spatiotemporal patterns. Instagram provides a great tool and network for users to 
showcase where they are, when they come and what they do. These data can, therefore, illustrate urban activities and evolution over space and time.

We proposed a framework that integrates the spatial-temporal distribution for different activity categories, the urban public spaces' check-in time and UPSs surrounding built environment. This paper aims to concentrate on the correlation between the distribution of active Instagram posts regarding UPSs in the different periods of time in a day, days of week, and between weekdays and weekends, offering an initial understanding of urban dynamics, and pointing out the UPSs which gain or lose attractiveness in each time slot over the course of the day. Subsequently, we analyzed the spatial distribution of popular space in 2-hour time slots. The results show that it is noteworthy that the permanently dense hotspots are also the most bustling and lively locations of HCMC in terms of individual density. Besides, stability both in space and time is also observed in the central city.

Finally, with what is revealed by new sources of delocalized data, an inevitable direction for further studies will be to bridge the existing knowledge about the influence of the environment on the attractiveness of urban space. This Instagram-based approach has enabled us to recognize visually that commercial-related public spaces play a dominant role in the urban dynamics of HCMC. Commercial spaces like retail areas are believed to be the most active in the evening and at the weekends, whereas open spaces host more activities in the morning on weekdays. This paper's finding is at odds with the urban planning stereotype that the surrounding environment such as public transportation (bus stop), public facilities (parks and shopping malls), and other commercial spaces, often help appeal people to get around. In the case of HCMC, it has proved the opposite: people are attracted to UPSs even though there are not many cultural and social specialties there.

This paper's research consolidates one assumption from our urban observation: different categories of urban spaces have different spatiotemporal patterns. Taking advantage of this newly emerging source of social network data makes it feasible to measure, analyze, model and predict. Consequently, this real-time spatiotemporal distribution can be a good estimation for further urban planning as the outcomes help to seek more insight into urban vibrancy in relation to diverse functional spaces. This is desirable because by understanding the link between activities and land use, governments and related organizations can predict future trend patterns of citizens' activity as well as new urban sustainable developments.

However, this research has some limitations. The approach in this paper overcomes the purely descriptive limitation by using KDE analysis in order to examine the attractiveness of different spaces in the two populous central districts on Instagram activity according to time slot. It is obvious that there are some limitations with Instagram data because it cannot represent the entire population of the city; therefore, we can use other social media platforms for future comprehensive research along with the Instagram data. If possible, researchers should obtain data from many social platforms within the whole city to create more objective and comprehensive understanding ho $\mathrm{w}$ vitality in relation to urban design. Other indicators for measuring facilities in urban surroundings as proposed by Prem Chhetri et al. [65] e.g, aesthetic, amenity, and social interaction should also be included in the model to gain more deeper understanding. Last but not least, in addition to the correlation coefficient applied in this paper, researchers could also try spatial regression model or ordinary least squares to look at the comparative relationship between each surrounding urban environment indicator with people's choice at any particular place.

\section{Data Availability Statement}

Some or all data, models, or code generated or used during the study are available from the corresponding author by request:

List of data generated or used during the study:

1. Point of interest data of Ho Chi Minh City collected from the Google map in 2017.

2. Check-in database collected from Instagram in 2016 and 2017 in Ho Chi Minh City.

3. Street map of Ho Chi Minh City collected in Open Street Map. 
Author Contributions: Conceptualization, H.H., T.V.T.N. and N.S.; Methodology: T.V.T.N.; Validation: H.H. and T.V.T.N.; Formal Analysis: T.V.T.N.; Investigation: H.H. and T.V.T.N.; Resource: H.H. and T.V.T.N.; Data Curation: T.V.T.N.; Writing-Original Draft Preparation: T.V.T.N.; Writing-Review and Editing: H.H., T.V.T.N. and N.H.; Supervision: H.H.; Funding Acquisition: H.H.

Funding: This research is funded by the National Natural Science Foundation of China, Project No.: 51778560.

Acknowledgments: We thank Xianfan Shu for his helpful advices and suggestions in ArcGIS analysis. We are grateful to Tram Ngoc Lam for her research assistance.

Conflicts of Interest: The authors declare no conflict of interest.

\section{References}

1. Dick, H.; Rimmer, P. Beyond the Third World City: The New Urban Geography of South-east Asia. Urban Stud. 1998, 35, 2303-2321. [CrossRef]

2. Shatkin, G. The City and the Bottom Line: Urban Megaprojects and the Privatization of Planning in Southeast Asia. Environ. Plan. A Econ. Space 2008, 40, 383-401. [CrossRef]

3. Madaniour, A. Why are the design and developement of public spaces significant for cities? Environ. Plan. $B$ Plan. Des. 1999, 26, 879-891. [CrossRef]

4. Carr, S.; Francis, M.; Rivlin, L.G.; Stone, A.M. Public Space; Cambridge University Press: Cambridge, UK, 1992.

5. Afacan, Y. Achieving Inclusion in Public Spaces: A Shopping Mall Case Study. In Designing Inclusive Systems; Springer: Berlin/Heidelberg, Germany, 2012; pp. 85-92.

6. Akkar Ercan, Z.M. Public spaces of post-industrial cities and their changing roles. METU J. Fac. Archit. 2007, 24, 115-137.

7. Chang, H.S.; Liao, C.H. Exploring an intergrated method for measuring the relative spatial equity im public facilities in the context of urban parks. Cities 2011, 28, 361-371. [CrossRef]

8. Kazemi, A.V.; Dousti, F.; Behzadfar, M. A New Reading of Sociable Public Spaces: The Nexus between Urban Design and Microsociology. Armanshaltr Archit. Urban Dev. 2018, 11, 39-49.

9. Rung, A.L.B.; Mowen, A.; Cohen, D.A. The significance of parks to physical activity and public health: A conceptual model. Am. J. Prev. Med. 2005, 28, 159-168. [CrossRef]

10. Ding, D.; Sallis, J.F.; Kerr, J.; Lee, S.; Rosenberg, D.E. Neighborhood environment and physical activities among youth. American Journal of Preventive Medicine. 2014, 41, 442-455. [CrossRef]

11. Ghavampour, E. The Contribution of Natural Design Elements to the Sustained Use of Public Space in a City Centre. Ph.D. Thesis, Victoria University of Wellington, Wellington, New Zeland, 2014.

12. Aspinall, P. On environmental preference: applying conjoint analysis to visiting parks and buying houses. In Innovative Approaches to Research Landscape and Health: Open Space: People Space 2; Routledge: Abingdon, UK, 2010.

13. Kaplan, R. The role of nature in the urban context. In Environment and Behaviroural Studies; Altman, I., Christensen, K., Eds.; Pelnum Press: New York, NY, USA, 1983.

14. Koohsari, M.J.; Kaczynski, A.T.; Giles-Corti, B.; Karakiewicz, J.A. Effects of access to public open spaces on walking: Is proximity enough? Landsc. Urban Plan. 2013, 117, 92-99. [CrossRef]

15. Schipperijn, J.; Stigsdotter, U.K.; Randrup, T.B.; Troelsen, J. Influences on the use of urban green space - A case study in Odense, Denmark. Urban For. Urban Green. 2010, 9, 25-32. [CrossRef]

16. Tzoulas, K.; Korpela, K.; Yli-Pelkonen, V.; Kazmierczak, A.; Niemela, J.; James, P. Promoting ecosystem and human health in urban areas using green infrastrucutre: A literature review. Landsc. Urban Plan. 2007, 81, 167-168. [CrossRef]

17. Chen, Y.; Liu, T.; Xie, X.; Marusic, B.G. What attracts people to visit community open spaces? A case study of the overseas Chinese town community in Shanzhen, China. Environ. Res. Public Health 2016, 13, 644. [CrossRef] [PubMed]

18. Coutts, C. Multiple Case Studies of the Influence of Land-Use Type on the Distribution of Uses along Urban River Greenways. J. Urban Plan. Dev. 2009, 135, 31-38. [CrossRef]

19. Han, H.; Sahito, N.; Nguyen, T.V.T.; Hwang, J.; Asif, M.; Nguyen, T.T. Exploring the Features of Sustainable Urban Form and the Factors that Provoke Shoppers towards Shopping Malls. Sustainability 2019, 11, 4798. [CrossRef]

20. Kaczynski, A.T.; Potwarka, L.R.; Smale, B.J.A.; Havitz, M.E. Association of Parkland Proximity with Neighborhood and Park-based Physical Activity: Variations by Gender and Age. Leis. Sci. 2009, 31, 174-191. [CrossRef] 
21. Sugiyama, T.; Gunn, L.D.; Christian, H.; Francis, J.; Foster, S.; Hooper, P.; Owen, N.; Giles-Corti, B. Quality of Public Open Spaces and Recreational Walking. Am. J. Public Health 2015, 105, 2490-2495. [CrossRef]

22. Brown, G. Mapping spatial attributes in survey research for natural resource managerment: Methods and applications. Soc. Nat. Res. 2005, 18, 17-39. [CrossRef]

23. Gehl, J.; Richard, L.R. Cities for People; Island Press: Washington, DC, USA, 2013.

24. Abaza, M. Shopping Malls, Consumer Culture and the Reshaping of Public Space in Egypt. Theory Cult. Soc. 2001, 18, 97-122. [CrossRef]

25. Stillerman, J.; Salcedo, R. Transposing the Urban to the Mall: Routes, Relationships, and Resistance in Two Santiago, Chile, Shopping Centers. J. Contemp. Ethnigr. 2012, 41, 309-336. [CrossRef]

26. Sui, D.; Goodchild, M. The convergence of GIS and Social media: Challenges for GISscience. Int. J. Geogr. Inf. Sci. 2011, 25, 1737-1748. [CrossRef]

27. Croitoru, A.; Wayant, N.; Crooks, A.; Radzikowski, J.; Stefanidis, A. Linking cyber and physical spaces through community detection and clustering in social media feeds. Comput. Environ. Urban Syst. 2014, 53, 47-64. [CrossRef]

28. Lin, J.; Cromley, R.G. Evaluating geo-located Twitter data as a control layer for areal interpolation of population. Appl. Geogr. 2015, 58, 41-47. [CrossRef]

29. Shelton, T.; Poorthuis, A.; Graham, M.; Zook, M. Mapping the data shadows of Hurricane Sandy: Uncovering the cocial soatial dimensions of big data. Geoforum 2014, 52, 167-179. [CrossRef]

30. Boyd, D.; Crawford, K. Critical questions for big data: provocations for a culture, technological, and scholarly phenomenon. Inf. Commun. Soc. 2012, 15, 662-679. [CrossRef]

31. Martí, P.; Serrano-Estrada, L.; Nolasco-Cirugeda, A. Using locative social media and urban cartographies to identify and locate successful urban plazas. Cities 2017, 64, 66-78. [CrossRef]

32. Zhai, S.; Xu, X.; Yang, L.; Zhou, M.; Zhang, L.; Qiu, B. Mapping the popurarity of urban restaurants using social media data. Appl. Geogr. 2015, 63, 113-120. [CrossRef]

33. Lane, N.D.; Eisenman, S.B.; Miluzzo, E.; Compbell, A.T. Urban sensing systems. In Proceedings of the 9th Workshop on Mobile Computing Systems and Applications-Hot Mobile, Napa Valley, CA, USA, 25-26 February 2008.

34. Noulas, A. Human Urban Mobility in Location-Based Social Networks: Analysis, Models and Applications; University of Cambridge: Cambridge, UK, 2013.

35. Silva, T.H.; De Melo, P.O.S.V.; Almeida, J.M.; Salles, J.; Loureiro, A.A.F. A comparison of Foursquare and Instagram to the study of city dynamics and urban social behavior. In Proceedings of the 2nd ACM SIGKDD International Workshop, Chicago, IL, USA, 11 August 2013.

36. Setha, L.; Taplin, D.; Scheld, S. Rethinking Urban Parks: Public Space and Cultural Diversity; University of Texas Press: Austin, TX, USA, 2005.

37. Oldenburg, R. The Great Good Place; Marlowe: New York, NY, USA, 1999.

38. Nguyen, T.V.T.; Han, H.; Sahito Nand Lam, N.T. The Bookstore-Café: Emergence of a New Lifestyle as a Third Place in Hangzhou, China. Space Cult. 2019, 22, 216-233. [CrossRef]

39. Low, S.; Smith, N. The Politics of Public Space; Routledge: New York, NY, USA, 2006.

40. Banerjee, T. The Future of Public Space:Beyond Invented Streets and Reinvented Places. J. Am. Plan. Assoc. 2001, 67, 9-24. [CrossRef]

41. Stock, K. Mining location from social media: A systematic review. Comput. Environ. Urban Syst. 2018, 71, 209-240. [CrossRef]

42. Song, C.; Koren, T.; Wang, P.; Barabasi, A.-L. Modelling the scaling properties of human mobility. Nat. Phys. 2010, 6, 818-823. [CrossRef]

43. Xiao, G.; Juan, Z.; Zhang, C. Travel mode detection based on GPS track data and Bayesian networks. Comput. Environ. Urban Syst. 2015, 54, 14-22. [CrossRef]

44. Tsou, M.-H.; Leitner, M. Visualization of social media: seeing a mirage or a message? Cartogr. Geogr. Inf. Sci. 2013, 40, 55-60. [CrossRef]

45. Preotiuc-Peotro, D.; Cohn, T. Mining user behaviours: A case study of check-in patterns in location based social networks. In Proceedings of the 5th Annual ACM Science Conference, Paris, France, 2-4 May 2013.

46. Frias-Martinez, V.; Soto, V.; Hohwald, H.; Frias-Martinez, E. Characterizing Urban Landscapes Using Geolocated Tweets. In Proceedings of the 2012 International Conference on Privacy, Security, Risk and Trust 
and 2012 International Confernece on Social Computing, Amsterdam, The Netherlands, 3-5 September 2012; pp. 239-248.

47. Xia, C.; Hu, J.; Zhu, Y.; Naaman, M. What Is New in Our City? A Framework for Event Extraction Using Social Media Posts. In Proceedings of the Computer Vision-ECCV 2012, Firenze, Italy, 7-13 October 2012; Springer: Berlin/Heidelberg, Germany, 2015; Volume 9077, pp. 16-32.

48. Hyvärinen, O.; Saltikoff, E. Social Media as a Source of Meteorological Observations. Mon. Weather Rev. 2010, 138, 3175-3184. [CrossRef]

49. Boy, J.D.; Uitermark, J. How to Study the City on Instagram. PLoS ONE 2016, 11, e0158161. [CrossRef]

50. Candia, J.; González, M.C.; Wang, P.; Schoenharl, T.; Madey, G.; Barabasi, A.-L. Uncovering individual and collective human dynamics from mobile phone records. J. Phys. A Math. Theor. 2008, 41, 224015. [CrossRef]

51. O'Sullivan, D.; Unwin, D. Geographic Information Analysis; John Wiley \& Sons: Hoboken, NJ, USA, 2003.

52. Agterberg, F.P. Interactive Spatial Data Analysis. Comput. Geosci. 1996, 22, 953-954. [CrossRef]

53. Silverman, B.W. Density Estimation for Statistics and Data Analysis; Chapman and Hall: London, UK, 1999.

54. Schabenberger, O.; Gotway, C.A. Statistical Methods for Spatial Data Analysis; Chapman and Hall: London, UK, 2017.

55. Miyake, K.K.; Maroko, A.R.; Grady, K.L.; Maantay, J.A.; Arno, P.S. Not Just a Walk in the Park: Methodological Improvements for Determining Environmental Justice Implications of Park Access in New York City for the Promotion of Physical Activity. Cities Environ. 2010, 3, 1-17. [CrossRef]

56. Correlation Coefficient: Simple Definition, Formula, Easy Steps. 2019. Available online: http: //www.statisticshowto.datasciencecentral.com/probability-and-statistics/correlation-coefficient-formula/ (accessed on 10 September 2019).

57. Waibel, M. Ho Chi Minh Mega City; Regio Spectra Verlag: Berlin, Germany, 2013.

58. Long, Y.; Huang, C.C. Does block size matter? The impact of urban design on economic vitality for Chinese cities. Environ. Plan. B Urban Anal. City Sci. 2019, 46, 406-422. [CrossRef]

59. Donahue, M.L.; Keeler, B.L.; Wood, S.A.; Fisher, D.M.; Hamstead, Z.A.; McPhearson, T. Using social media to understand drivers of urban park visitation in the Twin Cities. Landsc. Urban Plan. 2018, 175, 1-10. [CrossRef]

60. Curran, K.; Fisher, G.; Crumlish, J. OpenStreetMap. Int. J. Interact. Commun. Syst. Technol. 2012, 2, 69-78. [CrossRef]

61. Shen, Y.; Karimi, K. Urban function connectivity: Characterisation of functional urban streets with social media check-in data. Cities 2016, 55, 9-21. [CrossRef]

62. Duggan, M. Mobile Messaging and Social Media. 2015. Available online: https://www.pewinternet.org/2015/ 08/19/mobile-messaging-and-social-media-2015/ (accessed on 19 August 2015).

63. Carmona, M. Contemporary public space, part two: Classsification. J. Urban Des. 2010, 15, $123-148$. [CrossRef]

64. Wu, L.; Zhi, Y.; Sui, Z.; Liu, Y. Intra-Urban Human Mobility and Activity Transition: Evidence from Social Media Check-In Data. PLoS ONE 2014, 9, e97010. [CrossRef] [PubMed]

65. Prem, C.; Robert, S.; John, W. Modelling the Factors of Neighbourhood Attractiveness Reflected in Residential Location Decision Choices. Stud. Reg. Sci. 2006, 36, 393-417.

(C) 2019 by the authors. Licensee MDPI, Basel, Switzerland. This article is an open access article distributed under the terms and conditions of the Creative Commons Attribution (CC BY) license (http://creativecommons.org/licenses/by/4.0/). 